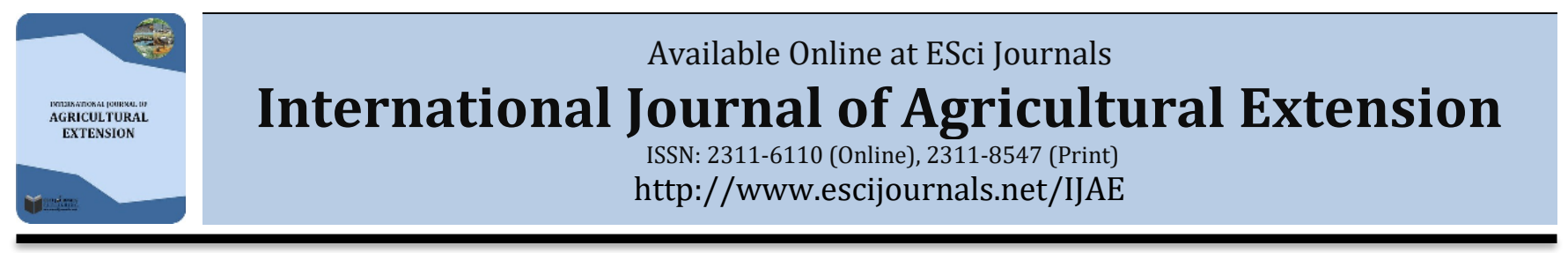

\title{
HOUSEHOLD REMOTENESS AND PATTERNS OF FOOD PRODUCTION AND CONSUMPTION IN TAJIKISTAN
}

\author{
Heather S. Anderson*, Elizabeth A. Wood, Agata Kowalewska, Nargiza Ludgate, Sarah McKune \\ University of Florida, Gainesville.
}

\begin{abstract}
A B S T R A C T
Malnutrition and micronutrient deficiencies are significant public health problems in the Central Asian country of Tajikistan, with over $26 \%$ of children under age 5 being stunted and $30 \%$ being anemic. The Khatlon Province is the country's largest agricultural area where people are often dependent on home gardens to ensure food security. The proximity of households to resources such as markets, roads, and infrastructure can affect food availability, diets, and diversity of agricultural products for consumption. This study aims to evaluate whether the remoteness of a household affects the production, consumption, and acquisition of specific crops among households in Khatlon Province, Tajikistan. A remote household was defined as one that is distant from markets and the main center of population, difficult to travel to, and has limited resources. This cross-sectional study used a household survey and focus groups to measure crop production, consumption, and food acquisition. Household surveys were administered to 107 households in six Khatlon districts and 15 focus groups were conducted in various rural villages within Khatlon. Data was analyzed using a two-sample t-test for the household surveys and NVivo software for capturing major themes within the focus groups. Results revealed that there was no statistically significant difference when comparing households for remoteness in regard to crop production, frequency of consumption, and acquisition. Frequency of food cons umption was similar when comparing remoteness but significantly decreased among all households when the crop was not in season. Programs that increase agricultural knowledge about production and extended growing season are extremely beneficial to improve nutrition in these vulnerable households. Additionally, gender-related concerns were discovered within the qualitative data such as the double burden of working to maintain crops as well as managing a household. Therefore, interventions based around agricultural production and acquisition should target women.
\end{abstract}

Keywords: Tajikistan, acquisition, remoteness, dietary diversity, agricultural extension.

\section{INTRODUCTION}

Tajikistan is the poorest and smallest country in Central Asia, with a size of $143 \mathrm{~km} 2$ and a population of 8 million (Bekturganov et al., 2016, World Bank, 2016). In 1992, following the collapse of the Soviet Union, the country suffered a civil war that resulted in infrastructure devastation, poverty, and population displacement. Tajikistan is landlocked and, unlike other Central Asian countries, lacks natural resources to provide a stable economy and jobs with a poverty rate of 42.8\% (World Bank, 2016). Emigration of men to find work has had a significant impact on families, with half

* Corresponding Author:

Email: hsaanderson@ufl.edu

(C) 2018 ESci Journals Publishing. All rights reserved. of households having at least one family member working abroad. Though agriculture is the base of the Tajik economy, it has changed since Tajikistan established its independence from the Soviet Union in 1991 (Grand et al., 2001). During the Soviet era the economy was generally characterized by intense, largescale cotton production, resulting in the neglecting of food crop production for consumption. Overtime, there has been continued deterioration of the soils and water supply system, making agriculture even more difficult. The World Bank estimates that only two-thirds of potential agricultural land is currently farmed because of the poor irrigation and lack of water, thus further decreasing the amount of arable land in the country (Jones et al., 2017). Environmental factors, such as 
increasing periods of drought or flood, also exacerbate the poor potential for agricultural production, resulting in greater food shortages (Grand et al., 2001). There are four types of agriculture production systems in Tajikistan: home gardens, presidential land, dekhkan farms, and agricultural enterprises (Jones et al., 2017). Home gardens (less than $0.1 \mathrm{ha}$ ) are located within the household compound and are used to grow crops consumed by the family. Presidential land (about 0.1 ha) is separate from homesteads and allocated to households with the intent to supplement home garden production for food security (Porteous, 2003). Dekhkan farms are medium sized commercial farms (on average 3 ha), which are also physically separate from home gardens. While the government owns the dekhkan farmland, families are entitled to lifelong and inheritable leases (International Monetary Funds, 2003). Agricultural enterprises are large farms that specialize in the production of commercial crops. Most households rely on homestead gardens for food security, and crops are cultivated mainly for consumption, but some crops are also sold for household income (World Bank, 2016).

Food insecurity, lack of nutritional diversity, low hygiene, and disease all contribute to malnutrition in Tajikistan (Food and Agriculture Organization, 2015; United Nations International Children's Emergency Fund [UNICEF], 2013). Many people cannot afford a more diverse, nutrient rich diet and lack the resources to purchase variety of foods (FAO, 2015). Vitamin A deficiency is estimated to affect $40 \%$ of children under five with iodine deficiency affecting 59\% of women of childbearing age and $53 \%$ of children under five (UNICEF, 2010). Although, stunting is multifactorial, major factors contributing to stunting are nutritional intake, hygiene, and sanitation of which all exist in rural Tajikistan. The proximity of households to resources such as markets, roads, and infrastructure can affect food availability, diet, and diversity of agricultural products for consumption.

United States Agency for International Development (USAID) Feed the Future Tajikistan Agriculture and Water Activity (TAWA) works with women through rural development assistance interventions that provide education on nutrition, sanitation, basic agricultural skills, crop management, and seek to empower women (USAID, 2016). These programs help families transition from large-scale cotton production to private small-scale cash and food crops production.

This research project was conducted to develop a baseline understanding of the consumption, production, and acquisition of specific food crops within Khatlon Province, Tajikistan through a household survey and focus groups. The study aimed to determine whether the remoteness of a household had an effect on crop production and frequency of crop consumption. A remote household is defined as a household that is distant from markets and the main center of population, difficult to travel to and has limited resources such as water and electricity. The data gathered will be used to develop recommendations for agricultural extension services addressing barriers to dietary diversity in the Feed the Future Zone of Influence (ZOI) in Khatlon Province. This cross-sectional study was developed and implemented as a collaborative research project between researchers from University of Florida (UF) and TAWA. Fieldwork was supported by students from the Tajikistan Agrarian University (TAU), UF, and TAWA extension home economists.

Table 1.19 Foods/Crops of Interest.

\begin{tabular}{lllll}
\hline Tomatoes & Sweet Peppers & Cucumbers & Apricots & Milk \\
Mung beans & Cauliflower & Eggplant & Bok Chopy & Cabbage \\
Turnips & Radish & Lima beans & Spinach & Potatoes \\
Sweet potatoes & Broccoli & Asparagus & Okra & \\
\hline
\end{tabular}

\section{MATERIALS \& METHODS}

This study used a two-prong approach that included developing and implementing a household dietary diversity survey as well as conducting focus groups to capture major themes around household-decision making. A cross sectional survey was developed as a collaborative research project between researchers from UF and TAWA. The mixed methods survey was administered as a paper questionnaire, structured to capture demographic information, frequency of 
consumption of 19 specific crops/foods (Table 1), common dishes prepared with these crops/foods, methods of acquisition, possible barriers to consumption, and crops grown by the households. The crops used in the survey were predetermined by the needs of TAWA and identified by Feed the Future Tajikistan as strategic crops. The surveys were kept anonymous to ensure the privacy of each households, all data has been aggregated at the district level. The questionnaire was translated into Tajik and accompanied by a color photo book with images of the crops described in the questionnaire to assure the respondents had a reference to the crop that were being asked about. Local Tajik partners reviewed the survey for cultural appropriateness and clarity. Prior to implementing the survey, the Tajik students from TAU were trained in survey delivery and data entry and acted as translators and enumerators. The surveys were administered in person in one of the local languages: Tajik, Russian, or Uzbek. The purpose of the study and the role of the participating institution were explained, and oral informed consent was obtained. Institutional Review Board approval was obtained through the University of Florida. Focus groups were conducted in rural villages to better understand household decisionmaking around food. Focus group participants were stratified by mothers, mothers-in-law, and men. Given that most of the young mothers' husbands were employed abroad, men in the villages were mostly older. Therefore, these three groups were targeted as they are what make up a traditional household within rural Khatlon Province. Focus group discussions were facilitated by female TAWA extension home economists for mothers and mothers-in-law and male TAU students facilitated the men's groups. Translations were occurring in real-time so that the UF students who were in attendance were able to transcribe, in English, the entire focus group. As with the survey, all facilitators were trained in qualitative data collection methods prior to conducting any focus groups. The study population was households in the Khatlon Province of Tajikistan. The dietary diversity questionnaire was administered in six out of the twelve districts of the USAID Feed the Future ZOI in Khatlon Province, Tajikistan. TAWA extension home economists selected the villages based on where they worked with women's agricultural training groups. Households involved in the trainings were targeted for data collection through the survey.
This strategy was taken because it allowed researchers the opportunity to enter these communities with the home economists acting as gatekeepers. Focus group participants were also from villages within the Zone of Influence to capture a more exploratory approach to remoteness and acquisition. Prior to fieldwork, the instruments for both the survey and focus groups were tested and adjusted appropriately. Participants for the survey were recruited by the extension home economists that were facilitating and translating throughout the discussions. Male TAU students were also utilized to recruit male participants. Overall, 107 household surveys were administered in six districts in the Khatlon Province: Yovon, Vakhsh, Shaatruz, Khuronson (Ghozimalik), Jomi, and Bokhtar districts (Figure 1). A total of 15 focus groups were conducted across five districts that consisted of seven focus groups with mothers, four with mothers-in-law, two with males, and two with mixed mothers-in-law and mothers. From each of the six targeted districts, two remote villages and two non-remote villages were selected to administer the survey. Remoteness was determined by TAWA, as a remote village was further distance from markets, difficult to access, and had limited resources.

Analysis: The data collected from the surveys was entered into Microsoft Excel and analyzed based on the collection method. The quantitative data was analyzed using Microsoft Excel.

A two-sample t-test was performed to determine whether there was statistical significance between remote and non-remote households. Once all focus groups were conducted and transcribed, two researchers independently combed through each transcript looking for major themes and sub-themes using the grounded theory as a framework to guide detection. Once this process was complete, NVivo software was used to validate all major themes and subthemes in order to have consensus across the two researchers.

\section{RESULTS}

The study population for the dietary assessment survey was women, ages 21 to 85, representing 107 households in USAID Feed the Future ZOI of Khatlon Province. These women participate in TAWA's empowerment and agricultural training groups. Majority of women were ethnic Tajiks but a few ethnic Uzbeks. Most of them were either the spouse of the head of household or were the heads of household themselves (Table 2). 


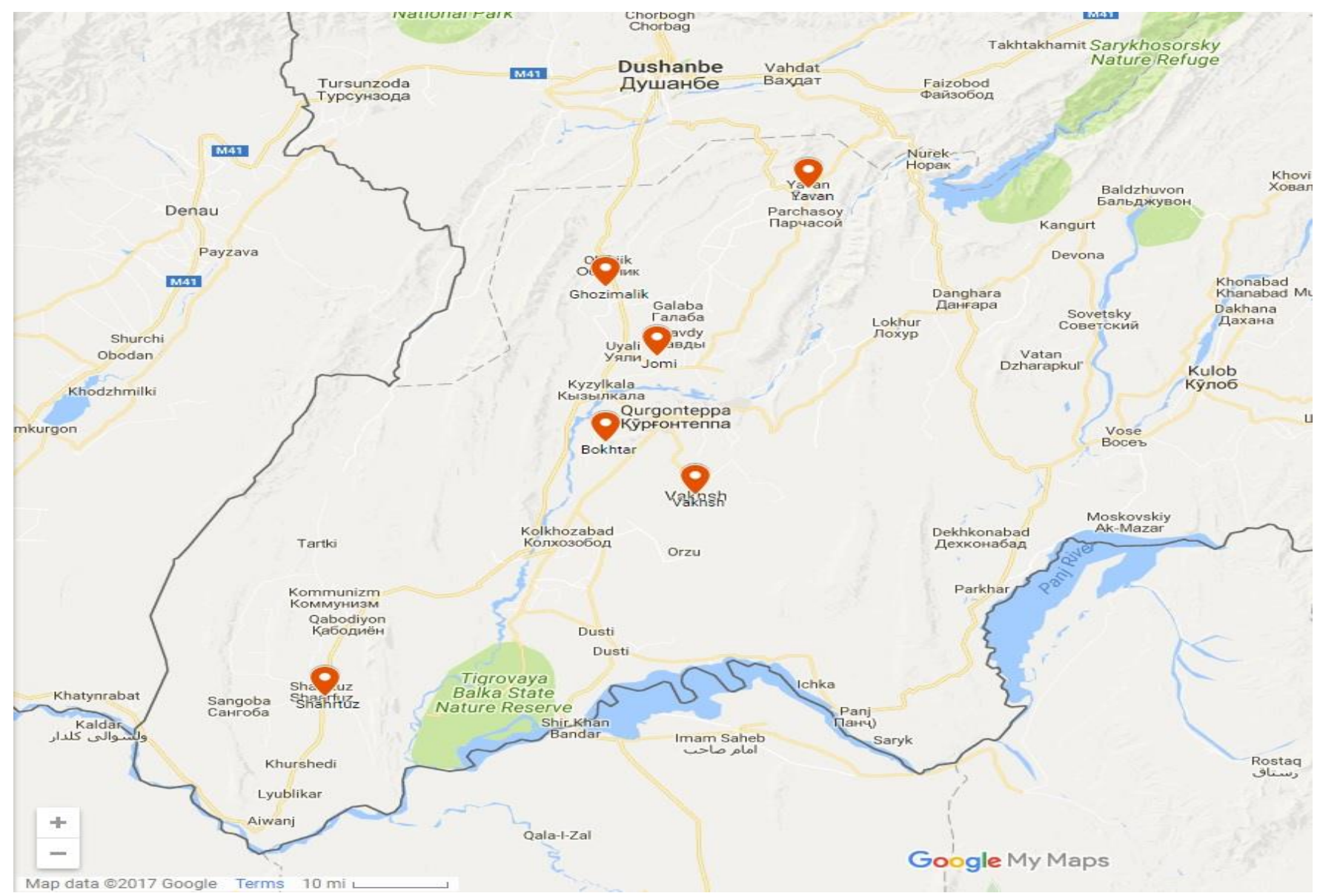

Figure 1. Location of Survey Data Collection in Khatloon Province of Tajikstan.

Table 2. Characteristics of Respondents.

\begin{tabular}{lc|lc|lc}
\hline \multicolumn{2}{|c|}{ Relationship to head of household } & \multicolumn{2}{|c}{ Occupation } & \multicolumn{2}{c}{ Education } \\
Spouse & $66 \%$ & Home-maker & $64 \%$ & Secondary school & $77 \%$ \\
Self & $15 \%$ & Farmer & $12 \%$ & Vocational school & $15 \%$ \\
Daughter-in-law & $8 \%$ & Scientist/ teacher & $14 \%$ & Bachelor's Degree & $3 \%$ \\
Daughter & $7 \%$ & Accountant & $4 \%$ & Soviet System & $3 \%$ \\
Mother & $4 \%$ & Farmer & $4 \%$ & & \\
& & Seamstress & $1 \%$ & \\
& & Midwife & $1 \%$ & & \\
\hline
\end{tabular}

Household Characteristics: Households were characterized by the location of their village, whether the village was considered to be remote or non-remote. There were 53 remote households and 54 non-remote households. A remote location was defined as a village that was further from the market, had limited resources, and difficult to travel to. The majority of households did not have a car and used a taxi or walked by foot if they needed to travel to the market. Remote households reported that it often took one hour to get to the market by taxi. A non-remote location was defined as being closer to a market, having more resources such as centralized water, electricity, food supplies, and being easier to access. Many of the non-remote villages also had access to small stores that serve as convenience stores with limited food items. The household members responsible for buying food were mostly the responding women or their spouse. The average number of people reported living in a single household was 7.4. Many women reported that only their husbands or brothers- 
in-law were permitted to go to the market to purchase food. The answers varied if a husband, father, or a brother were away from the household, which most often was related to job outside of Tajikistan. When asked who makes a decision about what meal to prepare, $69 \%$ stated themselves, $5 \%$ their spouse, $11 \%$ their mother-in-law, $12 \%$ their daughter-in-law, and $1 \%$ stated themselves and their daughters-in-law.

Household Crop Production: Of all the households surveyed, 104 (98\%) had home gardens, 69 (64\%) had presidential land, and 46 (43\%) had dekhkan farm. For indepth probing, the data was also analyzed by remote location and non-remote location as illustrated in the Figure 3.

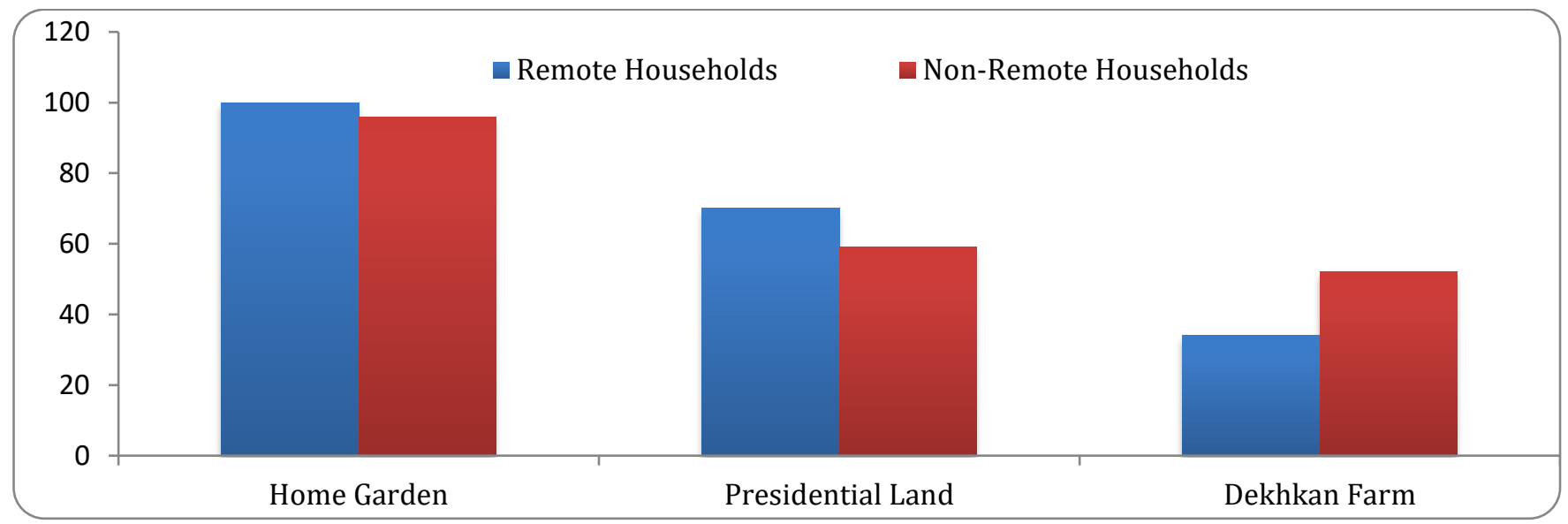

Figure 2. Percentage of households that have agricultural land by remoteness.

When comparing crop production for remoteness, there was not a significant difference between the proportions of households that grew the majority of the crops (Table 3). In general, both groups of households produced similar percentages of specified crops. The most common crops grown on home gardens were tomatoes, potatoes, sweet peppers, cucumbers, lima beans, eggplants, and apricots. The least common grown were broccoli, asparagus, okra, sweet potatoes, bok choy and brussel sprouts, as they are unfamiliar in the area. Although there was a significant difference in the percentages of remote households that reported growing more cauliflower, bok choy and sweet potatoes, this difference can likely be attributed to the crops being unfamiliar. For these particular three crops, the difference can be explained by one household in that village growing the crop and disseminating the information to neighbors within the village. Only $34 \%$ of remote households and $52 \%$ of non-remote households have dekhkan farms. The most frequently grown specified crop on dekhkan farms was tomatoes.

Household Crop Consumption: Households were asked about how frequently they consume these specific crops. Answers ranged from never to more than four times a day. The foods consumed in the highest frequencies were tomatoes, potatoes, and sweet peppers. Reasons for not consuming bok choy included barriers such as not being able to afford it, unable to grow it, not liking the taste, not having any information about it, and not knowing what it is. Similar reasons were given for mung beans, spinach, cauliflower, and turnips. These findings were reinforced by the focus group discussions where across all groups, all agreed that potatoes were among the most important crop within a Tajik household. Mothers and mothers-in-law mentioned the introduction of bok choy into the region, but none of the focus group participants in any group mention it as a staple or if it is preferred or not within the household. Households were also questioned about crops that are not common in the area, such as asparagus, broccoli, sweet potatoes, brussel sprouts and okra, and asked if they have ever eaten them and would they like to grow them. Only $5 \%$ of all respondents have ever eaten asparagus but $92 \%$ said that they would like to try and grow if they had more information. Similarly, $5 \%$ have eaten broccoli while $93 \%$ would like to try and grow it, and $8 \%$ have eaten okra and $93 \%$ would favor to cultivate these crops. In addition to the 18 plant-based crops, households were asked about the consumption of cow milk products. 
Table 3. Percentages of households that grow specific crops on their home garden, presidential land and Dekhkan farm by remoteness.

\begin{tabular}{lccccccccc}
\hline \multirow{3}{*}{ Crops } & \multicolumn{3}{c}{ Home Gardens } & \multicolumn{3}{c}{ Dekhkan Farms } & \multicolumn{3}{c}{ Presidential Land } \\
\cline { 2 - 10 } & Remote & $\begin{array}{c}\text { Non- } \\
\text { Remote }\end{array}$ & P-value & Remote & $\begin{array}{c}\text { Non- } \\
\text { Remote }\end{array}$ & P-value & Remote & $\begin{array}{c}\text { Non- } \\
\text { Remote }\end{array}$ & P-value \\
\cline { 2 - 10 } & $\mathrm{n}=53$ & $\mathrm{n}=54$ & & $\mathrm{n}=37$ & $\mathrm{n}=32$ & & $\mathrm{n}=17$ & $\mathrm{n}=28$ & \\
Tomato & 100 & 96 & 0.14 & 3 & 9 & 0.3 & 12 & 57 & 0.003 \\
Sweet pepper & 96 & 89 & 0.3 & 3 & 9 & 0.3 & 0 & 11 & 0.2 \\
Potato & 96 & 91 & 0.3 & 8 & 19 & 0.18 & 11 & 1 & 0.1 \\
Cucumber & 94 & 83 & 0.08 & 0 & 9 & 0.06 & 11 & 11 & 1 \\
Eggplant & 85 & 80 & 0.5 & 3 & 16 & 0.06 & 0 & 0 & NA \\
Apricot & 81 & 72 & 0.3 & 0 & 0 & NA & 0 & 1 & 0.6 \\
Lima bean & 79 & 72 & 0.4 & 0 & 13 & 0.03 & 6 & 3 & 0.6 \\
Cauliflower & 72 & 41 & 0.001 & 3 & 0 & 0.32 & 18 & 7 & 0.3 \\
Radish & 64 & 59 & 0.6 & 0 & 3 & 0.3 & 0 & 0 & NA \\
Cabbage & 62 & 46 & 0.1 & 0 & 3 & 0.3 & 0 & 0 & NA \\
Turnip & 51 & 65 & 0.1 & 0 & 3 & 0.3 & 0 & 0 & NA \\
Bok choy & 44 & 11 & 0.0001 & 0 & 0 & NA & 0 & 3 & 0.5 \\
Mung bean & 34 & 24 & 0.26 & 0 & 3 & 0.3 & 0 & 0 & NA \\
Sweet Potato & 32 & 9 & 0.003 & 0 & 0 & NA & 6 & 7 & 0.9 \\
Spinach & 23 & 24 & 0.9 & 0 & 0 & NA & 0 & 3 & 0.5 \\
\hline
\end{tabular}



Figure 3(a). Consumption frequency of certain crops in season and not in season.

Milk is consumed in $89 \%$ of remote and $94 \%$ of nonremote households. Households were also asked if they consumed any other animal dairy products, goat milk or cheese, and they all responded no.

The consumption frequency of each specific crop was compared by household location and there was no significant difference in consumption frequency when comparing remoteness of households. Both remote and non-remote households reported a significant decrease in consumption frequency for all crops except potatoes when the crop was not in season (Figure $3 \mathrm{a} \& \mathrm{~b}$ ). Potatoes did not have a seasonal variation due to existing knowledge for post-harvest storing and they do not require refrigeration. Within focus groups, many women (both mothers and mothers-in-law) mentioned the struggle of growing crops during the winter and the difficulty of having enough food for the household during this time, especially since this is when most men return briefly from working abroad, meaning less remittance income to a household to buy food. 


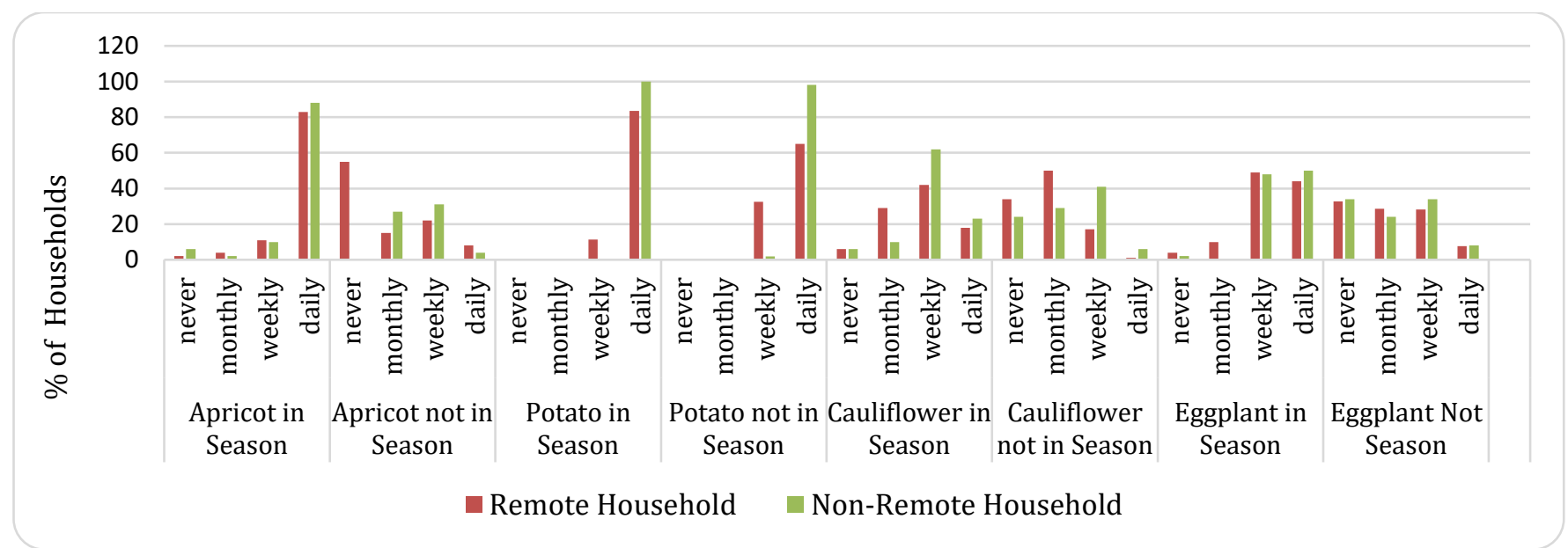

Figure 3(b). Consumption frequency of certain crops in season and not in season.

One mother-in-law (MiL) stated: "We buy the most food in the winter."

Mothers also stated this: "In winter time most [of] the time we buy potatoes, carrots, cabbage, and fish from the market. In summer time we buy not so much food from the market because we have land. In springtime we buy cucumber and tomatoes. For the fall and summer everything is grown from the land, so there is no need to go to the market."

Household Food Acquisition: Information regarding where households acquired specific foods was collected from the survey and supplemented by the focus group discussions. According to the survey, the majority of crops were grown in home gardens, followed by supplemental purchases from markets. Most households did not purchase these food crops from a store. This was echoed within focus groups; however, men were more likely to barter for food than the women who participated. Among most female groups, trading was mentioned but it was an informal occurrence that usually happened among neighbors. Both mothers and mothers-in-law also brought up how the local village store will allow tabs or other forms to allow women to pay at a later date, whereas at the district markets this was not expected or permitted.

MiL: "We buy foods from the market. Sometimes we buy foods from our neighbors"

Mother: "Mainly we buy foods from the store and also from the market."

While households in nearly all surveyed districts relied on home gardens to grow food, differences in food acquisition for specific crops are more pronounced when analysed by remoteness of the household. When comparing household food source by remoteness, a higher percentage of remote households use their home gardens as a food source for most crops. Both remote and non-remote households rely primarily on their home garden, their farm, and the market for food security (Figure 4).



Figure 4. Household food acquisition of select crops by remoteness. 
There is very little reported reliance on neighbors, bartering, or trade for food security. Statically significant differences exist between remote households and nonremote households for growing food crops from their garden and farm for tomatoes, sweet peppers, cucumbers, eggplant, and cauliflower. A higher percentage of non-remote households reported obtaining the food crops from their farm. Some villages had access to a small village store that sold limited food crops such as potatoes and tomatoes and household staples such as sugar. Most of the remote villages did not have a village store but relied on their household production or the district market. Women reported that it was difficult to get to the district market, in some villages it took an hour by taxi. There is much more food diversity at district market compared to villages stores.

One mother stated: "We don't trade for food; we always buy food with money. But sometimes we pay later for what we took."

MiL: "In the market they don't usually trade for food." Another MiL said: "I buy from [the district] market because we have less food in the village."

\section{DISCUSSION}

The findings of this study indicate that the production of these 19 plant-based crops is predominantly achieved within home gardens, with much less being produced on presidential land and dekhkan farms for household consumption. The households that were surveyed rely on home gardens for food security, where district markets were used more to supplement food sources and purchase non-crop-based food items such as sugar, tea, and cooking oil. Consumption was influenced by season, as a result of limited crops being grown in winter and a limited means to preserve crop harvest. This can be attributed to the households having limited to no electricity, making food preservation difficult. All women reported pickling or creating compote to preserve crop harvest for the off-season when these foods are not available. According to many women in the focus groups, men would return from working abroad during winter time when food resources are scarcest, and remittances shrink, placing an additional burden on households. Programs that increase agricultural knowledge and improve production practices including extended growing season, such as the TAWA trainings, are beneficial to all rural vulnerable households. Therefore, future research and interventions should appeal to seasonal variability and focus on ways to improve dietary diversity, specifically in the winter. Recent literature comparing food acquisition between remote areas or those that have limited access to markets is very sparse. Zerfu et al. (2016) reported that household food diversity is tied with household agricultural production as well as the distance to local or district markets. Stifel \& Minten (2017) studied the relationship between household well-being, nutrition and market access in Ethiopia. They found that remote households consume less, are more food insecure, and have less diverse diets. The authors also found no statistical difference between the relationship of market access and maternal and child nutrition outcomes. Birdi and Shah (2015) described similar findings where development of perennial home gardens had a direct effect on improved dietary diversity of the household and improved consumption of nutrient dense foods. The use of home gardens was more effective when paired with continuous agricultural education and with providing basic nutrition information about the health benefits (Birdi et al., 2015).

\section{CONCLUSION AND RECOMMENDATIONS}

This study did not show that remoteness factor was a significant indicator in crop production, consumption, or acquisition. However, it did illustrate that household food production is a factor that affects food diversity, food consumption, and is influenced by season.

Limitations are present in the current study due to several factors in design and data collection. The design did not allow villages and participants to be randomly selected, villages were chosen based on previous engagement with the local partner, TAWA, and participants represented TAWA's female empowerment trainings groups. This survey did not capture true dietary diversity since it only focused on 19 specific crops and milk that had been predetermined by USAID and local partners. The survey did not measure quantity of the food consumed, only frequency of consumption with in the households with potatoes being the major staple crop. Additional questions related to distance and how often trips were made to the market, and by whom, would be beneficial to future studies.

This study is significant to agriculture extension workers because households in the rural villages of Khatlon Province of Tajikistan depend on self-production of crops for food security. Agriculture extension service programs that improve agricultural practices and productivity, such as TAWA, are crucial to improving 
nutrition and increasing household food security in these areas.

These resource poor smallholder farms benefit from education and training provided by agricultural extension services, particularly training that helps diversify household gardens since, as this study demonstrates, this is the primary source of foods consumed by rural households. Many women expressed interest in learning new skills and trades that would empower them and help them earn income to lessen the burden of food insecurity, specifically in the winter months. In addition to providing agricultural training, it is beneficial to provide information and demonstrations about food preservation to help alleviate the significant drop in both food diversity and overall consumption during the lean season.

Acknowledgements and Disclaimer: This research was produced as part of the United States Agency for International Development (USAID) and US Government Feed the Future project "Integrating Gender and Nutrition within Extension and Advisory Services" (INGENAES) under the Leader with Associates Cooperative Agreement No. AID-OAA-LA-14-00008. The United States Agency for International Development is the leading American government agency building social and economic prosperity together with the government and people of Tajikistan. The University of Illinois at Urbana-Champaign is the prime awardee, and partners with the University of California-Davis, the University of Florida, and Cultural Practice, LLC. www.ingenaes.illinois.edu.

The research was made possible by the generous support of the American people through USAID. The contents are the responsibility of the authors and do not necessarily reflect the views of USAID or the United States government. The authors thank the Feed the Future Tajikistan Agriculture and Water Activity project that provided facilitators and logistical support, the Feed the Future Tajikistan Health and Nutrition Activity project, and the Tajikistan Agrarian University students as well as the University of Florida master's in public health students for their contributions.

\section{REFERENCES}

Action Against Hunger. (2007). Report on the Knowledge, Attitudes \& Practices (KAP) Survey: Breastfeeding and Complementary Feeding.

Ahmed, T., Hossain, M. \& Sanin, K. (2013). Global burden of maternal and child undernutrition and micronutrient deficiencies. Annals of Nutrition and Metabolism, 61(1),8-17.

Bekturganov Z, Tussupova K, Berndtsson R, Sharapatova $\mathrm{N}$, Aryngazin K, Zhanasova $\mathrm{M}$. WaterRelated Health Problems in Central Asia-A Review. Water,24,8(6),219.

Birdi, T. J., \& Shah, S. U. (2015). Implementing Perennial Kitchen Garden Model to Improve Diet Diversity in Melghat, India. Global Journal of Health Science, 8(4), 10.

Bhutta, Z. A. (2004). Maternal and child health: is South Asia ready for change? The British Medical Journal, 328(7443), 816-819.

Centers for Disease Control and Prevention (2004) NHANES Food Questionnaire.

De Sa, J., Bouttasing, N., Sampson, L., Perks, C., Osrin, D. \& Prost, A. (2012). Identifying priorities to improve maternal \& child nutrition among the Khmu ethnic group, Laos: a formative study. Maternal \& Child Nutrition, 9(4),452-466.

Ekwochi, U., $\quad$ Osuorah, C. D., $\quad$ Ndu, I. K., $\quad$ Ifediora, C., Asinobi, I. N., \& Eke, C. B. (2016). Food taboos and myths in South Eastern Nigeria: The belief and practice of mothers in the region. Journal of

Ethnobiology and Ethnomedicine, 12(1).

Food and Agricultural Organizations of the United Nations (2014). FAOSTAT. Retrieved from http://www.fao.org/faostat/en/\#country/208

Feed the Future Tajikistan. (2013). Baseline Household Survey U.S. Agency for International Development.

Grand JM, Leather C, Mason F. (2001) Tajikistan: What Role for Nongovernmental Organizations? Geopolitics of Hunger 2000-2001: Hunger and Power. Action Against Hunger. 2001; 63-73.

Jáuregui-Lobera, I. (2014). Iron deficiency and cognitive functions. Neuropsychiatric Disease and Treatment, 10:2087-2095.

Jones K, Hoover A. (2014). Tajikistan: Background Study. InnovATE: Innovation for Agriculture Training and Education. [cited 2017 Jan 22].

Lazarte, C. (2015). Integrating the minimum dietary diversity-women module into the household budget survey in Tajikistan.

Makkar, H. (2012). Status of animal nutrition research and development activities in Tajikistan, Kyrgyzstan and Azerbaijan. Rome: Food and Agriculture Organization of the United Nations. 
Nicolo, G., Nowak, V., Mak, Q., \& Lee, W. (2014). Project report on integration of the women's dietary diversity score into the household budget survey in Tajikistan, 2014.

Pandey, V. L., Mahendra Dev, S., \& Jayachandran, U. (2016). Impact of agricultural interventions on the nutritional status in South Asia: A review. Food Policy, 62, 28-40.

Porteous, O. (2003). Land reform in Tajikistan: From the capital to cotton fields. Action Against Hunger.

Quin M., Wang D., Watkins WE., Gebski V., Yan YQ., Li M., Chen ZP. (2005). The effects of iodine on intelligence in children: a meta-analysis of studies conducted in China. Asia pacific Journal of Nutrition. 14(1),32-42.

Statistical Agency under the President of the Republic of Tajikistan (SA), Ministry of Health [Tajikistan], and ICF International. (2013). Tajikistan Demographic and Health Survey 2012. Dushanbe, Tajikistan, and Calverton, Maryland, USA: SA, $\mathrm{MOH}$, and ICF International.

Stifel, D., \& Minten, B. (2017). Market Access, Well-being, and Nutrition: Evidence from Ethiopia. World Development, 90, 229-241.
The World Bank. (2017). Tajikistan. Retrieved January 26, 2017, from http://www.worldbank.org/en/country/tajikista

$\mathrm{n}$

United Nations International Children's Emergency Fund. (2010). Micronutrient status survey in Tajikistan, 2009.

United Nations International Children's Emergency Fund. (2013). Situational Analysis Improving Economic Outcomes by Expanding Nutrition Programming in Tajikistan. Washington, DC: World Bank.

United States Agency for International Development. (2004). Land Reform and Farm Reorganization in Tajikistan. Retrieved from http://pdf.usaid.gov/pdf_docs/Pnadd469.pdf

United States Agency for International Development. (2016). In Tajikistan, Feed the Future Trains Women to Take Charge of Nutrition. Feed the Future.

Zerfu, T. A., Umeta, M., \& Baye, K. (2016). Dietary habits, food taboos, and perceptions towards weight gain during pregnancy in Arsi, rural central Ethiopia: a qualitative cross-sectional study. Journal of Health, Population and Nutrition, 35(1). 